\title{
AFLATOXINS AND FUMONISINS CONTAMINATION OF HOME-MADE FOOD (WEANIMIX) FROM CEREAL-LEGUME BLENDS FOR CHILDREN
}

\author{
J. KUMI ${ }^{1}$, N. J. MITCHELL ${ }^{2}$, G. A. ASARE ${ }^{4}$, E. DOTSE ${ }^{1}$, F. KWAA ${ }^{3}$, T. D. PHILLIPS ${ }^{2}$ and N-A \\ ANKRAH ${ }^{1}$ \\ ${ }^{1}$ Noguchi Memorial Institute for Medical Research, University of Ghana, Accra, Ghana, ${ }^{2}$ Texas A\&M Uni- \\ versity, College Station, Texas, USA, ${ }^{3}$ Ejura Sekyedumase District Hospital, Ejura, Ashanti Region, Ghana, \\ ${ }^{4}$ School of Allied Health Sciences, University of Ghana, Accra, Ghana
}

DOI: http://dx.doi.org/10.4314/gmj.v48i3.2

Corresponding Author: Professor Nii-Ayi Ankrah

Email:NAnkrah@noguchi.ug.edu.gh

Conflict of Interest: None declared

\section{SUMMARY}

Background: Weanimix is an important food for children in Ghana. Mothers are trained to prepare homemade weanimix from beans, groundnuts and maize for their infants. Groundnuts and maize are prone to aflatoxin contamination while fumonisin contaminates maize. Aflatoxin, is produced by the Asperguillus fungi while fumonisin, is produced by Fusarium fungi. These mycotoxins occur in tropical areas worldwide due to favorable climate for their growth.

Objective: The objective of the study was to determine the levels of aflatoxin and fumonisin in homemade weanimix in the Ejura-Sekyedumase district in the Ashanti Region of Ghana.

Methods: Thirty six homemade weanimix samples (50g each) were collected from households. Aflatoxin and fumonisin were measured using a fluorometric procedure described by the Association of Official Analytical Chemist (AOAC official method 993.31, V1 series 4).

Results: Aflatoxin and fumonisin were detected in all 36 samples, range $7.9-500 \mathrm{ppb}$. Fumonisin levels range: $0.74-11.0 \mathrm{ppm})$. Thirty $(83.3 \%)$ of the thirty six samples were over the action limit of $20 \mathrm{ppb}$ for aflatoxin with an overall mean of $145.2 \mathrm{ppb}$ whiles $58.3 \%$ of the samples had fumonisins above the action limit of 4 ppm with an overall mean of $4.7 \mathrm{ppm}$.

Conclusion: There were significant aflatoxin and fumonisin contamination of homemade weanimix. Children fed on this nutritional food were being exposed to unacceptable levels of aflatoxin and fumonisin. Therefore there is a critical need to educate mothers on the dangers of mycotoxin exposure and to develop strategies to eliminate exposure of children fed homemade weanimix to aflatoxin and fumonisin.

Keywords: Aflatoxin, Fumonisin, Home-made Weanimix, infants.

\section{INTRODUCTION}

Human exposures to mycotoxins have raised worldwide concerns due to their negative effect on health. In sub-Sahara Africa, aflatoxins and fumonisins contamination of food have been associated with increased incidence of hepatocellular carcinoma in the presence of hepatitis B virus (HBV) infection ${ }^{1}$ and esophageal cancer respectively. ${ }^{2}$ Aflatoxins $\mathrm{B}_{1}\left(\mathrm{AFB}_{1}\right)$ being the most potent are produced on various food crops including maize and groundnuts by Aspergillus flavus and Aspergillus parasiticus. Fumonisins $\mathrm{B}_{1}\left(\mathrm{FB}_{1}\right)$ are produced primarily in maize by Fusarium verticulliode and $F$. monoliforme. ${ }^{3}$

Environmental conditions typical of tropical countries favour the formation of both of these mycotoxins in food crops.Acute exposure to $\mathrm{AFB}_{1}$ in excess of $2 \mathrm{ppm}$ is known to cause nonspecific liver damage, maliase and death in few days. ${ }^{4,5}$ Chronic $\mathrm{AFB}_{1}$ exposure via consumption of contaminated foods (20ppb or more) is associated with immune suppression ${ }^{6}$ and nutritional deficiencies. ${ }^{7} \mathrm{FB}_{1}$ also suppresses the immune system, causes deficiency in nutrients such as folic acid ${ }^{8}$ and the modification of sphingomyelin metabolism .

$\mathrm{AFB}_{1}$ exposure in children increases significantly following weaning and stunting in children. ${ }^{10}$ Studies have shown that, saliva $\operatorname{IgA}(\mathrm{sIg} A)$ was markedly lower in children with detectable $\mathrm{AFB}_{1}$ level of $50.4 \mu \mathrm{g} \mathrm{AF}-$ lysine/mg protein compared with those with nondetectable levels. ${ }^{7}$

These observations indicate that exposure to $\mathrm{AFB}_{1}$ and $\mathrm{FB}_{1}$ could negatively affect the Expanded Programme of Immunization (EPI), recovery from illness and development with consequences for achieving Primary Health Care goals in tropical countries, Ghana included. 
Ghanaian foods prepared to eat ${ }^{11}$ or unprepared obtained from both urban and rural areas and sold in public markets ${ }^{12}$ were shown to be highly contaminated with aflatoxins with levels ranging from (5.7-22,168 $\mathrm{ppb}$ ) in groundnuts and groundnuts products. Coexposure to $\mathrm{AFB}_{1}$ and $\mathrm{FB}_{1}$ has been demonstrated in persons living at Ejura-Sekyedumase district in the Ashanti region, Ghana. ${ }^{13,14}$ In an effort to increase nutritional status and child growth, mothers of the children are taught to prepare a nutritional food, "weanimix" which is designed for children who are newly weaned from breastfeeding (approximately 6 months-2 years in age).

It is worth noting that maize and groundnuts, usually contaminated with $\mathrm{AFB}_{1}$ and $\mathrm{FB}_{1}$, are important food crops for homemade weanimix in Ghana. However data is not readily available on the safety, with respect to mycotoxins, of homemade weanimix fed to children in selected communities in Ghana. In this study, we seek to find out the extent of dietary intake of $\mathrm{AFB}_{1}$ and $\mathrm{FB}_{1}$ in homemade weanimix fed to children in selected communities in Ghana.

\section{MATERIALS AND METHODS}

\section{The study site and population}

The study was carried out at Ejura-Sekyedumase district in the Ashanti Region of Ghana and located in the transition zone between the Northern and Southern zones of the country. Previous work in this district showed high exposure rates of aflatoxins with $100 \%$ of people $(n=180)$ screened testing positive for the $\mathrm{AFB}_{1}$ albumin biomarker of exposure and $75 \%$ testing positive for urinary biomarkers of exposure. ${ }^{15}$ Thirty-six mothers who were trained by the Nutrition Department of the Ejura-Sekyedumase District hospital on weanimix preparation were recruited and consented for their participation in the study. Study participants were from the following three communities in the district, Hiawoawu, Dromankuma and Ejura town.

\section{Materials}

Vicam AflaTest and FumoniTest kits were used according to the Association of Official Analytical Chemists' method (AOAC) for aflatoxin and fumonisin analysis in weanimix, respectively (AOAC official method 993.31, V1 series 4). Sodium chloride $(\mathrm{NaCl})$ and HPLC grade methanol were purchased from Sigma-Aldrich Chemical Co. (St. Louis, MO). AflaTest and FumoniTest immunoaffinity columns were purchased from VICAM (Watertown, MA, USA). All other chemicals and reagents used were of highest purity available and commercially purchased.

\section{Homemade weanimix preparation}

The mothers prepared weanimix by mixing groundnuts, beans and maize, in the ratio 0.5:0.5:4.0 respectively. The food items were purchased on the open market at Ejura. The mixture was roasted for about 20 minutes and milled to obtain the homemade weanimix powder. The latter was used to prepare porridge for feeding of children.

A $100 \mathrm{~g}$ sample of the homemade weanimix powder was collected from each of the 36 mothers participating in the study and kept in sterile zip-locked bags at room temperature. The samples were labeled with individual identity codes and transported at room temperature to the Noguchi Memorial Institute for Medical Research in a sealed sterile transport box for analysis of aflatoxins and fumonisins.

\section{Sample processing and analysis \\ Weanimix Aflatoxin Analysis (Aflatest)}

Briefly, $25 \mathrm{~g}$ of the weanimix powder was blended with $5 \mathrm{~g} \mathrm{NaCl}$ and $125 \mathrm{ml}$ of the extraction solution $(70 \%$ methanol) in a covered blender jar at high speed for 2 minutes. The extract was then filtered twice; first through fluted filter paper and then with a glass microfiber filter $(90 \mathrm{~mm}, 1.0 \mu \mathrm{m})$. The eluent was collected in a clean beaker. Deionized water $(30 \mathrm{ml})$ was added to $15 \mathrm{ml}$ of the eluent and mixed thoroughly.

The resulting diluent was then filtered again through a glass microfiber filtered. Fifteen milliliters $(15 \mathrm{ml})$ of the filtered eluent was passed through Aflatest column at the rate of 1-2 drops/second. The column was washed twice with $10 \mathrm{ml}$ deionized water at the rate of 1-2 drops/second. This was followed by elution with $1.0 \mathrm{ml}$ HPLC grade methanol at the rate of 1-2 drops/second and collected in a glass cuvette. Aflatest developer (VICAM) was prepared daily. One milliliter $(1 \mathrm{ml})$ of the developer was mixed thoroughly with the eluent and the concentrations of aflatoxins were measured at a fluorescence detection of $425 \mathrm{~nm}$ using a calibrated fluorometer (VICAM, series 4, detection limit was $2 \mathrm{ppb}$ ).

\section{Fumonisin analysis}

The procedure for fumonisin determination was similar for the aflatoxin but with minor changes. Briefly, $50 \mathrm{~g}$ of milled sample was blended with $5 \mathrm{~g} \mathrm{NaCl}$ and $100 \mathrm{ml}$ of the extraction solution ( $80 \%$ methanol) in a covered blender jar at high speed for 1 minute. The extract was then filtered twice, diluted 4 -fold with $0.1 \%$ Tween-20 and refiltered and was passed through Fumonitest column. This was eluted with $1.0 \mathrm{ml} \mathrm{HPLC}$ grade methanol and mixed with the fumonitest developer. 
After 4 minutes the concentration of total fumonisin was measured at a fluorescence detection of $483 \mathrm{~nm}$ with detection limit of $0.2 \mathrm{ppm}(2 \mathrm{mg} / \mathrm{kg})$.

\section{Statistical analysis}

Data from the three communities were analyzed with JMP version 9 (SAS Institute Inc. Cary, NC USA). The data was subjected to simple descriptive statistics, which looked at the range, the mean and the variance.

\section{RESULTS}

A total of 36 weanimix samples were collected from 3 different communities in the Ejura-Sekyedumase district (12 samples from each community) and analyzed for total aflatoxins and fumonisins. Of those samples all $(100 \%)$ were positive for aflatoxin with $83.34 \%$ of the samples exceeding a concentration of $20 \mathrm{ppb}$; the action limit set forth by the U.S. Food and Drug Administration (U.S. FDA). Fumonisin was also present in all weanimix samples collected with $58.3 \%$ over the U.S. FDA limit of 4 ppm.
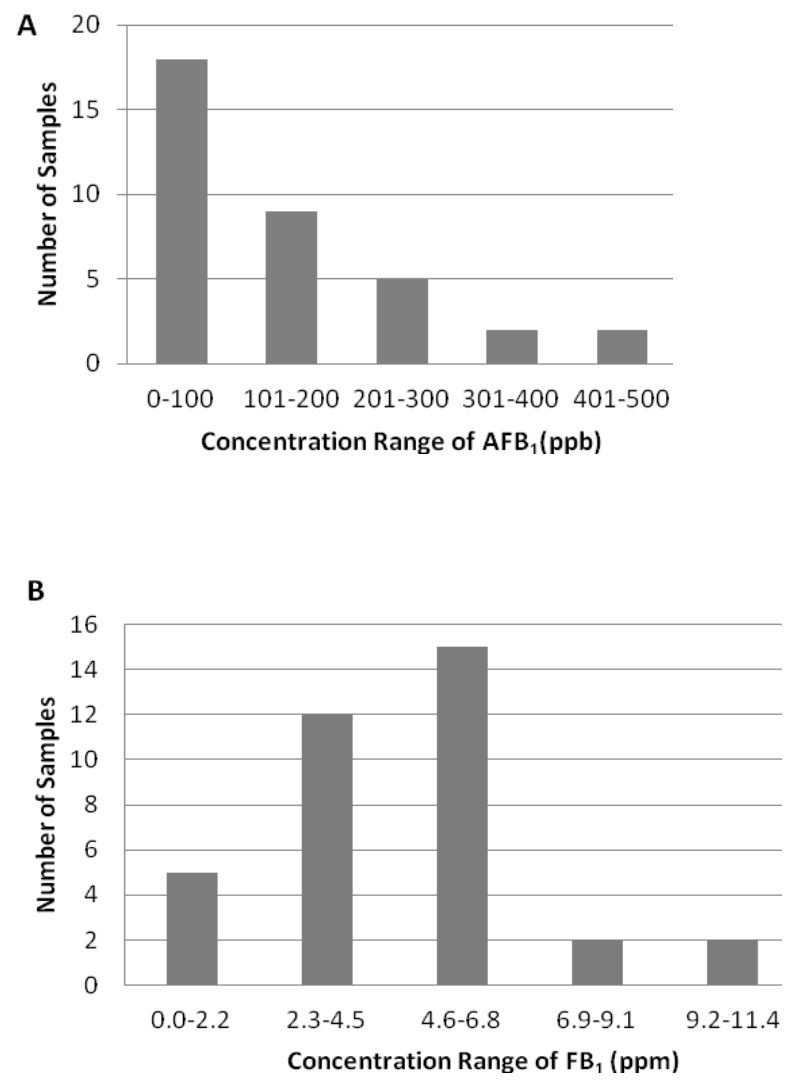

Figure 1 Range and Concentration of Aflatoxin and Fumonisin in Weanimix. - (A) Aflatoxin $\left(\mathrm{AFB}_{1}\right)$ concentration. (B) Fumonisin $\left(\mathrm{FB}_{1}\right)$ concentrations.

The range of aflatoxin concentrations from the three communities was 7.9-500 ppb with 9 samples over 200 ppb (Figure 1a) and fumonisins ranged from 0.75-11.0 ppm (Figure 1b).

Aflatoxin concentrations in weanimix varied from community to community with Ejura town having the highest with mean value of $209.4 \mathrm{ppb}$ and a range of 23-470 ppb, Hiawoawu had a range of 7.9-380 ppb with a mean concentration of $115.2 \mathrm{ppb}$ and Dromankuma had a range of $14-500 \mathrm{ppb}$ with a mean concentration of $111.1 \mathrm{ppb}$ (Figure 2a). The mean aflatoxin level in the homemade food for children at Dromankuma (111.1ppb) was significantly $(\mathrm{p}<0.05)$ lower when compared with the level (209.4ppb) obtained at Ejura town. The data on fumonisin showed no significant $(p>0.05)$ difference in the fumonisin concentrations between the three communities (Figure 2b). The fumonisin values ranged from $0.74-11.0 \mathrm{ppm}$ with a mean of $5.4 \mathrm{ppm}$ in Ejura town, 1.9-6.8 ppm with a mean of $4.2 \mathrm{ppm}$ in Hiawoawu and Dromankuma had a range of 1.5-11.0 ppm with a mean of $4.3 \mathrm{ppm}$.

A

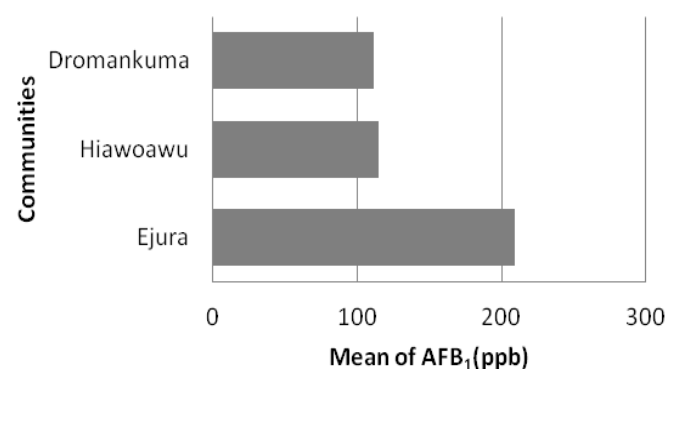

B

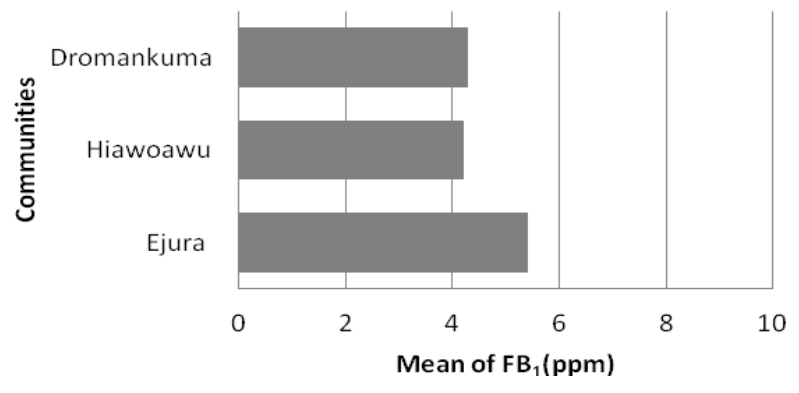

Figure 2 Mean of aflatoxin concentrations in Weanimix. (A) Aflatoxin $\left(\mathrm{AFB}_{1}\right)$ concentration. (B) Fumonisin $\left(\mathrm{FB}_{1}\right)$ concentrations. 


\section{DISCUSSION}

Weaning is a transition period of a child from breast milk to other sources of food which often results in a marked decrease in nutrient intake in developing countries. ${ }^{16}$ One possible variable contributing to poor child health is the increase in exposure to mycotoxin contaminated foods following weaning. The present studies have shown that, homemade weanimix meant to improve child nutrition is significantly contaminated with the mycotoxins, aflatoxin and fumonisin.

Aflatoxin exposure early in life has been associated with impaired growth, particularly stunting. ${ }^{17}$ This early exposure is a potential risk for synergistic interactions with other toxins as subjects grow in later years. ${ }^{18,9}$ Other studies elsewhere in Africa have shown high levels of aflatoxin contamination in staple foods. In a study $55 \%$ of maize products in Kenya had aflatoxin levels greater than the action limit of $20 \mathrm{ppb}, 35 \%$ of the products have levels exceeding $100 \mu \mathrm{g} / \mathrm{kg}$ and $7 \%$ above $1000 \mu \mathrm{g} / \mathrm{kg}$ as reported. ${ }^{20} \mathrm{~A}$ survey in 38 cities and towns in Benin, Togo and Ghana, showed $\mathrm{AFB}_{1}$ contamination of maize grains from market stores in the range of $24-117.5 \mu \mathrm{g} / \mathrm{kg}, 0.7-108.8 \mu \mathrm{g} / \mathrm{kg}$, and $0.4-490.7 \mu \mathrm{g} / \mathrm{kg}$ respectively. ${ }^{21}$ In the present study aflatoxin levels in homemade weanimix ranged from $7.9-500 \mathrm{ppb}(\mathrm{ug} / \mathrm{kg})$. The data obtained showed that two out of the 36 samples (from different communities) have levels of 460 and $500 \mathrm{ppb}(\mathrm{ug} / \mathrm{kg})$.

Fumonisins have been found in maize samples worldwide, with levels of $\mathrm{FB}_{1}$ reaching $>10 \mathrm{ppm}$ in the United States and $>100 \mathrm{ppm}$ in parts of Africa. ${ }^{22}$ Studies in Cote d'Ivoire ${ }^{23}$ and Ghana ${ }^{24}$ have shown cooccurrence of aflatoxins and fumonisins in maizebased foodstuffs. The present study shows that, $83.3 \%$ of homemade weanimix contaminated with aflatoxin was above the action limit of 20ppb and $58.3 \%$ of the weanimix contaminated with fumonisin was above the action limit of $4 \mathrm{ppm}$. This indicates that, the consumption of contaminated groundnuts and maize in these communities is likely to be very high.

In a study involving anaemia among pregnant women in Ghana, strong association was shown between aflatoxin and women with malaria and even stronger when those with iron deficiency anaemia were excluded, there appeared to be a risk of low birth weights when high levels of blood aflatoxin biomarker $(>11.34 \mathrm{pg}$ $\mathrm{AFB}_{1} / \mathrm{mg}$ albumin) were observed in pregnant women. $^{25}$

In another study involving 507 Ghanaian participants, $\mathrm{AFB}_{1}$-lysine adduct levels were statistically higher in subjects who had low levels of both vitamins A and $\mathrm{E}$ compared to subjects who had high vitamins A and $\mathrm{E}^{26}$ A cohort study involving 472 Gambian children of ages 6-9 years were recruited for analysis of possible correlation of aflatoxin exposure and immune status. Immune parameters included secretory $\operatorname{IgA}(\operatorname{sg} A)$ in saliva and cell-mediated immunity (CMI). It was found out that, saliva IgA (sIgA) was markedly lower in children with detectable aflatoxin-lysine compared with those with non-detectable levels of $50.4 \mu \mathrm{g} / \mathrm{mg}$ protein. ${ }^{7}$

The co-occurance of (70.8\%) of aflatoxins and fumonisins contaminations seen in this study with the $53 \%$ as reported by ${ }^{27}$ indicates about 0.74 -fold increase which may be due to poor storage conditions of the maize, groundnuts and beans used to prepare weanimix. The toxicosis that $\mathrm{AFB}_{1}$ and $\mathrm{FB}_{1}$ cause in humans and animals as well as the possible carryover of aflatoxins into consumable animal products, such as milk and infant feed is of widespread concern for child health in Sub-Saharan African countries. ${ }^{28}$

The results of the present study suggest that very young children from the Ejura-Sekyedumase district of the Ashanti Region of Ghana are likely to be exposed to high levels of aflatoxin from consumption of Aflatoxin contaminated homemade weanimix. The possible consequences on child immunity and growth in the district warrant further studies.

\section{CONCLUSION}

From this study homemade weanimix, an important food for feeding very young children was found to be highly contaminated with aflatoxin and fumonisin. This could negatively impact their health with respect to immunity and growth faltering, particularly stunting. The observations emphasize the need for aflatoxin exposure intervention strategies in high-risk countries, possibly targeted at the weaning period. Therefore there is a critical need to educate mothers on the dangers of mycotoxins exposure and to develop an economically feasible strategy to eliminate exposure of children fed homemade weanimix to aflatoxin and fumonisin.

\section{ACKNOWLEDGEMENT}

The study was supported by a grant from The Peanut Collaborative Research Program, TAM 149 USAID. The Authors are also grateful to Mr. Ebenezer OforiAtta of Clinical Pathology department, Noguchi Memorial Institute for Medical Research for his technical support. 


\section{REFERENCES}

1. International Agency for Research on Cancer Monographs on the Evaluation of Carcinogenic Risks to Humans: Some Naturally Occurring Substances: Food Items and Constituents, Heterocyclic Armonatic Amines and Mycotoxins. 2002. IARC Scientific Publications no.56. IARC, Lyon.

2. Stockmann-Juvalla $\mathrm{H}$ and Savolainen K. "A review of the toxic effects and mechanisms of action of fumonisin B1". Human \& Experimental Toxicology. 2008; 27 (11): 799-809.

3. Martins ML, Martins HM, Bernardo F. Aflatoxins in spices marketed in Portugal. Food. Addit. Contam. 2001;18 (4):315-9

4. Center for Disease Control and Prevention. Outbreak of aflatoxin poisoning Eastern and Central Provinces, Kenya. 2004. Morb. Mortal . 2004; 53:790-3

5. Ozturk M. p53 mutation in hepatocellular carcinoma after aflatoxin exposure. Lancet.1991; 338:1356-9

6. Ali MV, Mohiuddin SM, Reddy MV. Effect of dietary aflatoxin on cell mediated immunity and serum proteins in broiler chicken. Indian Vet. 1994 ;J 71:760-2

7. Turner PC, Moore SE, Hall AJ, Prentice AM, Wild CP. Modification of immune function through exposure to dietary aflatoxin in Gambian children. Environ. Health Persp. 2003 ;( 111):217-220.

8. Blom HJ, Shaw GM, Heijer M, Finnell RH. Neural tube defects and folate: case far from closed. Nat. Rev Neurosci. 2006;7(9):724-31

9. Stockmann-Juvalla $\mathrm{H}$ and Savolainen K. "A review of the toxic effects and mechanisms of action of fumonisin B1". Human \& Experimental Toxicology. 2008: 27 (11): 799-809.

10. Gong YY, Egal S, Hounsa A, Turner PC, Hall AJ, Cardwell KF, Wild CP. Determinants of aflatoxin exposure in young children from Benin and Togo, West Africa: the critical role of weaning. Int. J. Epidemiol 2003;32: 556-562.

11. Ankrah NA, Ekuban FA, Asamoah EB. Depressant effect of very low levels of aflatoxin B1 on mouse glyoxylase-I activity and methylglyoxal disposal. Biochem Pharmacol . 1990; 39(7):1261-3

12. Awuah RT, Kpodo KA. High incidence of Aspergillus flavus and aflatoxins in stored groundnut in Ghana and the use of a microbial assay to assess the inhibitory effects of plant extracts on aflatoxin synthesis. Mycopathologia. 1996; 134(2):109-14.

13. Jolly P, Jiang Y, Ellis W, Awuah R, Nnedu O, Phillips T, Wang Js, Afriyie-Gyawu E, Tang L, Person S, Williams J, Jolly C. Determinants of aflatoxin levels in Ghanaians: sociodemographic factors, knowledge of aflatoxin and food handling and con- sumption practices. Int J Hyg Environ Health. 2006; 209(4):345-58.

14. Robinson A, Johnson NM, Strey A, Taylor JF, et al. Calcium montmorillonite clay reduces urinary biomarkers of fumonisin $\mathrm{B}_{1}$ exposure in rats and humans. Food Addit. Contam. Part A Chem Anal Control Expo Risk Assess. 2012:29(5):809-18.

15. Wang P, Afriyie-Gyawu E, Tang Y, Johnson NM, $\mathrm{Xu} \mathrm{L}$, Tang L, Huebner HJ, Ankrah NA, OforiAdjei D, Ellis W, Jolly PE, Williams JH, Wang JS, Phillips TD. NovaSil clay intervention in Ghanaians at high risk for aflatoxicosis: II. Reduction in biomarkers of aflatoxin exposure in blood and urine. Food Additive and Contaminants. Part A Chem Anal Control Expo Risk Assess. 2008; 25(5):62234

16. Susheela TP, Narasinga-Rao BS. Energy density of diet in relation to energy intake of pre-school children from urban and rural communities of different economic status. Human Nutr Clin Nutr 1983; 37: 133-137.

17. Gong YY, Cardwell K, Hounsa A, Turner PC, Hall AJ, Wild CP. Dietary aflatoxin exposure and impaired growth in young children from Benin and Togo: cross sectional study. $\mathrm{Br}$ Med J. 2002; 325:20-1.

18. Asare GA, Bronz M, Naidoo V, Kew MC. Interactions between aflatoxin $\mathrm{B}_{1}$ and dietary iron overload in hepatic mutagenesis. Toxicoology. 2007; 234(3):157-66.

19. Kew MC. Synergistic Interaction between Aflatoxin B1 and Hepatitis B Virus in Hepatocarcinogenesis Liver Int. 2003:23(6):405-9.

20. Lewis L, Onsongo M, Schurz-Rogers, H., Luber G. et al. Aflatoxin Contamination of Commercial Maize Products during an Outbreak of Acute Aflatoxicosis in Eastern and Central Kenya. Environ. Health Persp. 2005;113(12): 1763-1767.

21. James B. Adda C, Cardwell K, et al. Public information campaign on aflatoxin contamination of maize grains in market stores in Benin, Ghana and Togo. Food Addit Contam. 2007; 24(11):1283-91.

22. International Agency for Research on Cancer Monographs on the Evaluation of Carcinogenic Risks to Humans: Some Naturally Occurring Substances: Food Items and Constitutents, Heterocyclic Armonatic Amines and Mycotoxins, 2002. IARC Scientific Publications no. 56. IARC, Lyon.

23. Sangare-Tigori B, Moukha S, Kouadio HJ, Betbeder AM, Dano DS, Creppy EE. Co-occurrence of aflatoxin B1, fumonisin B1, ochratoxin A and zearalenone in cereals and peanuts from Côte d'Ivoire. Food Addit Contam 2006; 23(10):1000-7.

24. Kpodo K, Thrane U, Hald B. Fusaria and fumonisins in maize from Ghana and their co- 
occurrence with aflatoxins. Int J Food Microbio. 2000; 1; 61(2-3):147-57.

25. Shuaib FM, Jolly PE, Ehiri JE, et al. Association between birth outcomes and aflatoxin B1 biomarker blood levels in pregnant women in $\mathrm{Ku}-$ masi, Ghana. Trop Med Int Health. 2010; 15(2):160-7.

26. Tang L, Xu L, Afriyie-Gyawu E, et al. Aflatoxinalbumin adducts and correlation with decreased serum levels of vitamins $\mathrm{A}$ and $\mathrm{E}$ in an adult Ghanaian population. Food Addit Contam. Part A Chem
Anal Control Expo Risk Assess. 2009; 26(1):10818.

27. Kpodo K, Thrane U, Hald B. Fusaria and fumonisins in maize from Ghana and their cooccurrence with aflatoxins. Int $J$ Food Microbio 2000; $1 ; 61(2-3): 147-57$.

28. Williams JH, Phillips TD, Jolly PE, Stiles JK, Jolly CM, Aggarwal D. Human aflatoxicosis in developing countries: a review of toxicology, exposure, potential health consequences and intervenetions Am. J. Clin. Nutr 2004;80:1106-1122 